\title{
Dilatometric Study of Two based Aluminium Sheets
}

\author{
Saadallah $\mathbf{S}^{1 *}$, Benaissa $\mathrm{A}^{2}$, Boubertakh $\mathrm{A}^{1}$ and Hamamda $\mathbf{S}^{1}$ \\ ${ }^{1}$ Laboratoire TTSM, Département de Physique, Université Constantine1, Algérie \\ 2Université M'Hamed Bouguerra, Université Boumerdes, Algérie
}

\begin{abstract}
The aim of the present work is dilatometric study, within the range from room temperature to $550^{\circ} \mathrm{C}$, of two aluminum based sheets containing some alloying elements in different proportions. The level of the Mn concentration in sheet 1 is higher than that in the sheet 2. But, the Fe concentration in the latter sheet is important compared to that of former one. The different proportions of alloying elements could be the origin of the remarkable difference in the thermal expansion behavior of the two studied sheets. It is important to note that both sheets are anisotropic. The thermal expansion coefficient measured along the perpendicular direction to the rolling plane of the sheet 1 containing a considerable amount of $\mathrm{Mn}$, as a function of temperature, is 3.5 times less than that of the sheet 2 containing a considerable amount of Fe. The observed weak thermal expansion coefficient in the case of the sheet 1 is explained by the strengthening of the interatomic bonds and the interaction forces. The use of complementary techniques of investigations such as Transmission electron Microscopy (TEM), scanning electron microscopy (SEM) and energy dispersive (EDS) chemical analysis reveal the presence of thermally stable particles, especially, in sheet 1.
\end{abstract}

Keywords: Dilatometry; Calorimetry; Anisotropy; Dispersoids; Phases transitions

\section{Introduction}

Among the targets of the scientific community is to improve the understanding of the physical phenomena which present new products and especially those that underwent different stresses. This knowledge could help for getting new materials with very interesting dynamic and thermodynamic characteristics [1].

The introduction of alloying elements in aluminium could be the origin of significant changes in its physical and, especially, thermodynamic properties. The addition of $\mathrm{Si}$ and $\mathrm{Mg}$ to aluminium with suitable teneurs could significantly improve the mechanical properties of the obtained products [2-8]. AlMgSi alloys are widely used in the automotive industry due to the compromise between weight reduction and improved mechanical properties [2]. The $\mathrm{Mg} / \mathrm{Si}$ ratio plays a predominant role on the precipitation sequence in these alloys. Although, these systems have been extensively studied, there are still some ambiguities which justify new approaches and detailed studies. Thus, several alloys were subjected to several research works published in different journals. However, the anisotropy detected, by dilatometry technique, along the three different directions of the studied sheets, was very little studied. Only few dilatometric studies have been conducted on aluminium sheets [9-11]. It has been showed that the thermal expansion coefficient changes as a function of temperature depends upon the direction along which the measure has been performed. The purpose of the present work is to understand deeply the behavior of the AlMgSi sheets in point of view dilatometric approaches along three directions.

\section{Experimental Procedure}

The chemical compositions of the studied two sheets are summarized in the following Table 1. We emphasize that both sheets contain the same alloying elements, except the level of some of them varies from one sheet to another. For example, the concentration of manganese in sheet 1 is higher than that in sheet 2 . Also, the latter material contains more $\mathrm{Mn}$ than that of the former one.

The thickness of the studied sheets is about $1.35 \mathrm{~mm}$. For dilatometric study, samples have been taken from each sheet as follow:
- Three samples have been taken along the direction parallel to the rolling direction (X direction);

- Three other specimens have been taken along the direction perpendicular to the rolling direction in rolling plane (Y direction);

- The last three specimens have been taken along the direction perpendicular to the rolling plane ( $\mathrm{Z}$ direction).

The thermal expansion coefficient $\alpha(\mathrm{T})$ measurements were performed in the temperature range $20-550^{\circ} \mathrm{C}$, using a dilatometer Netszch 402C. The a (T) curves versus temperature were obtained with a precision of about $10^{-7}{ }^{\circ} \mathrm{C}^{-1}$. Scanning electron microscopy (SEM) study has been carried out using a Philips 505 operating at $20 \mathrm{keV}$, equipped with an energy dispersive X-ray detector ( EDS ). Transmission electron microscopy (TEM) study has been carried out using a Philips EM 400T TEM operating at $120 \mathrm{keV}$. Samples for TEM study were prepared by jet electropolishing technique using a Struers Tenupol Unit using a solution of nitric acid-methanol $(1: 3)$ at $-30^{\circ} \mathrm{C}$ and a voltage of $15 \mathrm{~V}$.

\section{Results and Discussions}

Thermal expansion coefficients changes of samples of the sheet 1 versus temperature, measured along $\mathrm{X}, \mathrm{Y}$ and $\mathrm{Z}$ directions, are shown in Figure 1.

It is important to note that the thermal expansion coefficient $\alpha(\mathrm{T})$ curves of the studied materials showed different dilatometric behavior depending upon the direction along which the analysed sample has

*Corresponding author: Saadallah S, Laboratoire TTSM, Département de Physique, Université Constantine1, Algérie, Tel/Fax: +21331811173; E-mail: sorormet@yahoo.fr

Received October 16, 2014; Accepted January 22, 2015; Published January 30 , 2015

Citation: Saadallah S, Benaissa A, Boubertakh A, Hamamda S (2015) Dilatometric Study of Two based Aluminium Sheets. J Material Sci Eng 4: 150. doi:10.4172/2169-0022.1000150

Copyright: (c) 2015 Saadallah S, et al. This is an open-access article distributed under the terms of the Creative Commons Attribution License, which permits unrestricted use, distribution, and reproduction in any medium, provided the original author and source are credited. 


\begin{tabular}{|c|c|c|c|c|c|c|c|c|c|c|c|c|}
\hline Sheet & $\mathbf{S i}$ & Mg & $\mathrm{Cu}$ & $\mathrm{Fe}$ & Mn & $\mathrm{Cr}$ & $\mathrm{Ni}$ & $\mathrm{Ti}$ & $\mathbf{V}$ & $Z n$ & $\mathrm{Zr}$ & Al \\
\hline 01 & 0.520 & 1.080 & 0.300 & 0.300 & 0.120 & 0.210 & 0.011 & 0.024 & 0.006 & 0.011 & 0.001 & Balance \\
\hline 02 & 0.540 & 1.030 & 0.340 & 0.420 & 0.050 & 0.210 & 0.014 & 0.016 & 0.006 & 0.016 & 0.001 & Balance \\
\hline
\end{tabular}

Table 1: Chemical compositions of the two studied sheets.

been taken. The shape of the thermal expansion coefficients curves of for samples taken along $\mathrm{X}$ and $\mathrm{Y}$ directions appear to be similar, as they present similar dilatometric anomalous which correspond to different reactions of the precipitation sequences of this alloy as reported in the literature [12-16] are as follows:

$$
\alpha(\mathrm{SSS}) \rightarrow \text { GP zones } \rightarrow \beta^{\prime \prime} \rightarrow{ }^{\prime} \rightarrow \beta
$$

where $\alpha$ (SSS) is the supersaturated solid solution; GP zones are generally spherical clusters with unknown structure; $\beta$ " precipitates are fine needle shaped zones with monoclinic structure and are generally present in $\mathrm{Al}$ alloys aged to the maximum hardness; $\beta^{\prime}$ is rod shaped precipitates with hexagonal structure and are found in the over aged specimens. The $\beta\left(\mathrm{Mg}_{2} \mathrm{Si}\right)$ is an equilibrium phase in the precipitation sequence.

The shift of the peak reaction, attributed to the GP zones formation, towards higher temperatures for the samples taken from $\mathrm{X}$ and $\mathrm{Y}$ directions is the unique remark that can be seen from the corresponding curves. For example, the difference in temperature between the two maxima seen in the curves of the samples corresponding to $\mathrm{X}$ and $\mathrm{Y}$ directions (Figure 1) is about $30^{\circ} \mathrm{C}$. This difference in temperature between these two maxima could be related to the presence of a preferred orientation, as these materials have been cold and hot rolled during the fabrication process. Because, the presence of defects favour the formation of precipitates $[10,11]$. We note that the $\mathrm{X}$ direction coincides with the rolling direction. The peak corresponding to the GP zones formation for samples taken from $\mathrm{Z}$ direction is located in the same temperature range as those of the two others. It is important to note that the thermal expansion coefficient changes of the sample taken along $\mathrm{Z}$ direction is substantially lower than those corresponding to the samples corresponding to the two other directions. The height of its GP zones formation peak, is estimated to be less than half compared to those obtained from samples taken from $\mathrm{X}$ and $\mathrm{Y}$ directions.

Figure 2 shows that the thermal expansion coefficient curves, corresponding to samples taken from the three directions, appear to be similar. The different dilatometric anomalous are practically located in the same temperature range, whether measured along $\mathrm{Z}$ direction or along the two other directions. Moreover, the heights of the first peak corresponding to the zone GP formation of the thermal expansion coefficient (in the case of samples taken from $\mathrm{X}$ and $\mathrm{Y}$ directions), which appear to be equal. Whereas, the thermal expansion coefficient measured along $\mathrm{Z}$ direction, $\alpha_{\mathrm{z}}(\mathrm{T})$, is significantly larger than those measured along $X$ and $Y$ directions, denoted $\alpha_{x}(T)$ and $a_{Y}(T)$, respectively. This suggests the presence of a strong anisotropy in this material along this direction. While, $\alpha_{X}(T)$ and $\alpha_{Y}(T)$ are practically overlapped over the entire temperature range. This result is very important compared to those observed for the samples measured along $\mathrm{X}$ and $\mathrm{Y}$ directions. It is pprobably attributed to the presence of clusters of $\mathrm{Mg}$ or $\mathrm{Si}$ and/or the co-clusters of $\mathrm{Mg}$ and Si along this direction. The presence of dilatometric anisotropy in the two studied sheets is due to the rolling process, which is responsible for the creation of a high level of defects.

The next section is reserved to a comparative study of the thermal

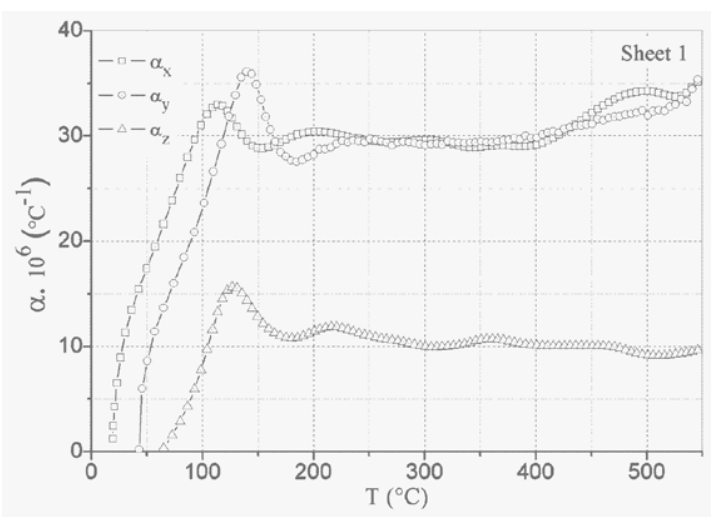

Figure 1: Thermal expansion coefficients changes versus temperature of samples of sheet 1 , measured along $X, Y$ and $Z$ directions.

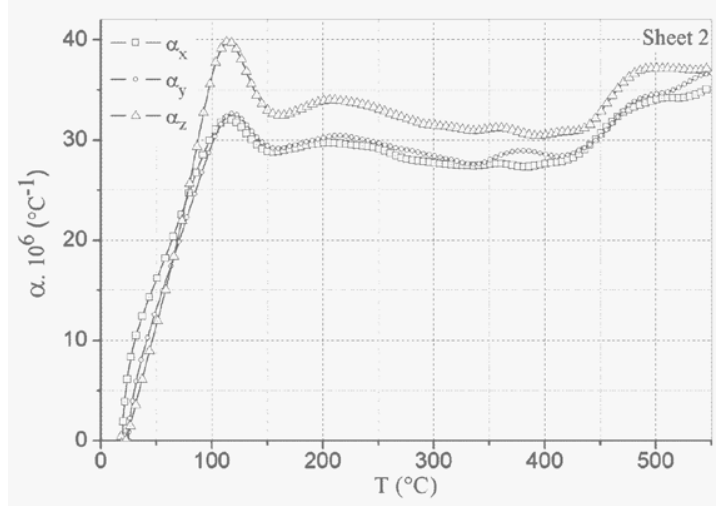

Figure 2: Thermal expansion coefficients changes versus temperature of samples of sheet 2 , measured along $X, Y$ and $Z$ directions.

expansion coefficient changes of the two sheets measured along $\mathrm{Z}$ direction.

Dilatometric measurements of the two sheets along the direction perpendicular to the rolling plan ( $Z$ direction) showed that the thermal expansion coefficient of the sheet $1,{ }_{\mathrm{Z1}}(\mathrm{T})$, is less compared to that of the sheet $2, \alpha_{\mathrm{Z} 2}(\mathrm{~T})$, over the entire temperature range. One can see a weak peak at around $40^{\circ} \mathrm{C}$, in the case of $a_{\mathrm{Z} 1}(\mathrm{~T})$ curve which does not appear in the case of the $\alpha_{\mathrm{zz}}(\mathrm{T})$ curve. This is probably due to the easy formation of clusters of solute in sheet 1 compared to that in sheet 2 $[17,18]$. At $120^{\circ} \mathrm{C}$, the height of the dilatometric peak for the case of sheet 2, is 4 times higher than that of the sheet 1 . Beyond $200^{\circ} \mathrm{C}, \mathrm{a}_{\mathrm{z} 1}(\mathrm{~T})$ curve appears almost linear and does not exceed $10.10^{-6{ }^{\circ}} \mathrm{C}^{-1}$. Whereas, the $\alpha_{72}(T)$ curve, which is linear too, is clearly higher than $35.10^{-60} \mathrm{C}^{-1}$. The dilatometric peak located at around $500^{\circ} \mathrm{C}$, in the case of sheet 1 , is probably due to the coarsening and/or dissolution of the phase and other particles.

At $550^{\circ} \mathrm{C}$, we can see that the ratio $\left[\alpha_{\mathrm{Z} 2}(\mathrm{~T}) / \alpha_{\mathrm{z} 1}(\mathrm{~T})\right]$ is about 4 . The observed weak expansion along $\mathrm{Z}$ direction in the case of the sheet 


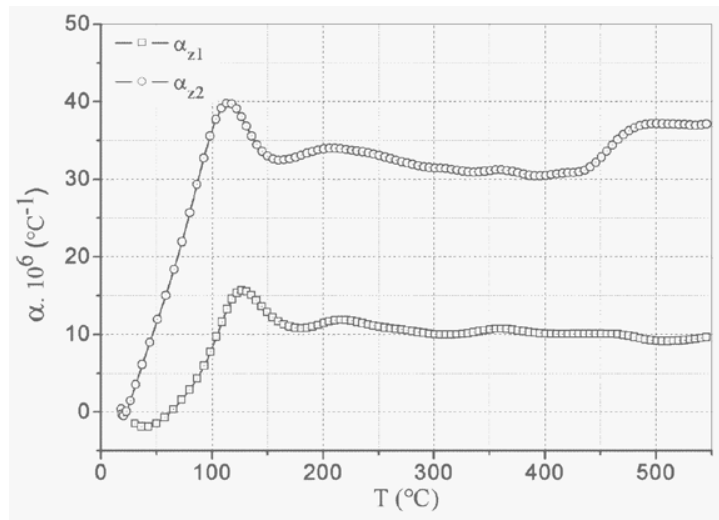

Figure 3: Thermal expansion coefficient changes, measured along $Z$ direction, of the two sheets versus temperature.

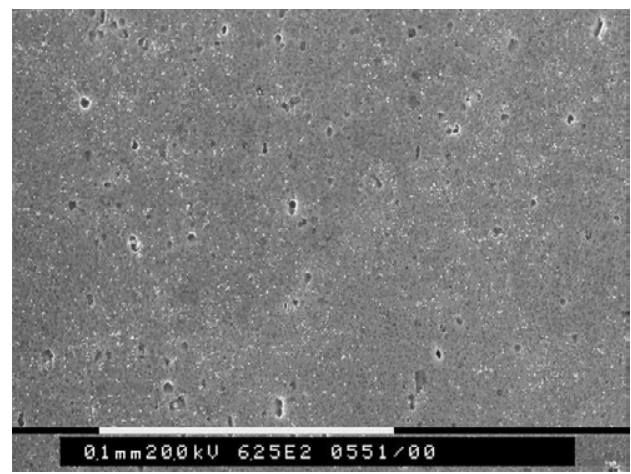

Figure 4: A Typical SEM micrograph showing the distribution of particles present in the as received sheets.

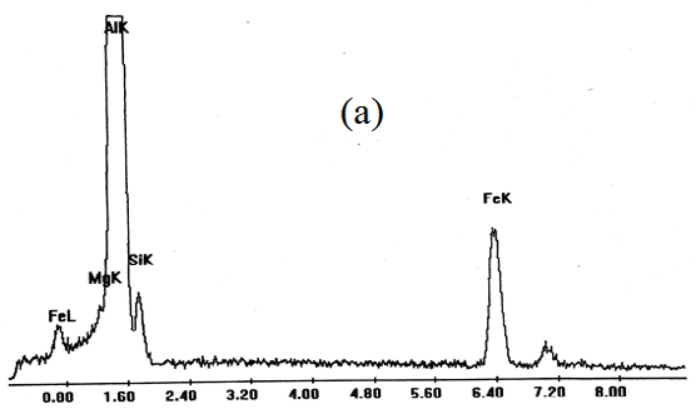

Figure 5a: EDS Spectrum obtained from particles seen by SEM in the as received sheets: Particlescontaining Fe and Si.

1 compared to that of the sheet 2 is attributed to different levels of transition elements present in the studied two sheets. The presence of the bearing located between $250-550^{\circ} \mathrm{C}$ in the case of $\alpha_{\mathrm{z} 1}(\mathrm{~T})$ curve showed a good resistance to thermal shock of sheet 1 compared to sheet 2, (Figure 3).

SEM observations of both of the as received sheets revealed the presence of particles, (Figure 4). Chemical analysis using X-ray energy dispersive (EDS) of the particles observed by SEM microscope showed the presence of particles, containing $\mathrm{Fe}$ and $\mathrm{Si}$, in sheet 2(with 0.42wt.\% Fe), (Figure 5a). While, sheet 1 (with 0.12 wt. \% Mn) contains a relatively low volume fraction of these particles. This mean of investigation reveals, also, the presence of particles containing $\mathrm{Fe}$

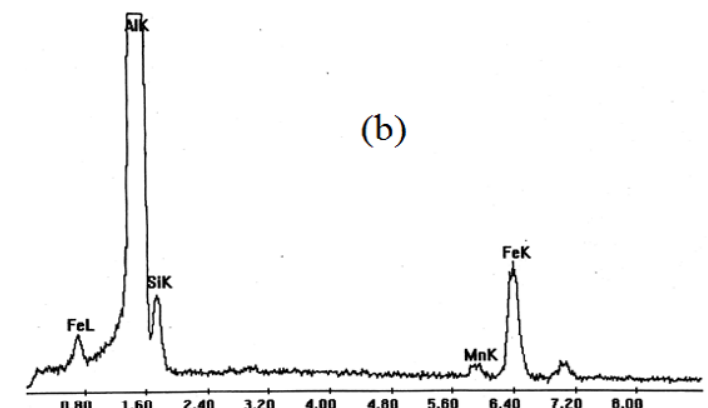

Figure 5b: EDS Spectrum obtained from particles seen by SEM in the as received sheets: Particles containing $\mathrm{Fe}, \mathrm{Mn}$ and $\mathrm{Si}$

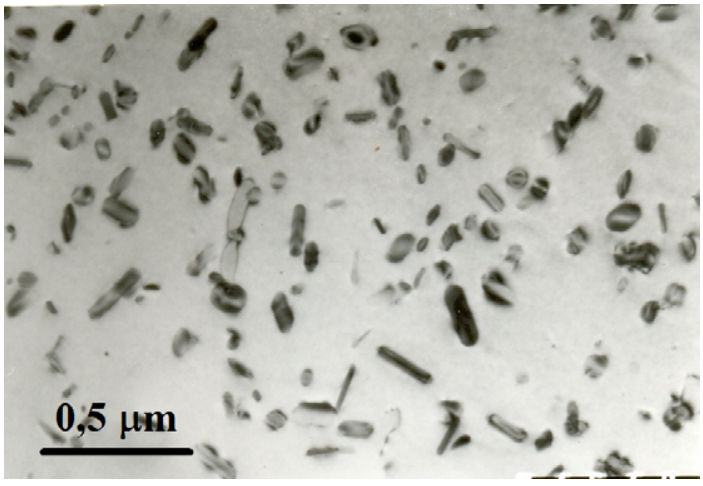

Figure 6: TEM Micrograph of the as received sheet 1 showing plate like particles containing $\mathrm{Mn}, \mathrm{Fe}$ and $\mathrm{Si}$ with the other one that does not contain Mn.

and $\mathrm{Mn}$ in addition to $\mathrm{Si}$, (Figure $5 \mathrm{~b}$ ). The particles containing $\mathrm{Mn}, \mathrm{Fe}$ in addition to $\mathrm{Si}$, appear to be stable at high temperatures and could improve the mechanical properties of the material.

Transmission electron microscope investigation of the as received sheets revealed the presence of plate like particles which contain $\mathrm{Fe}$ and $\mathrm{Mn}$ transition elements in addition to $\mathrm{Si}$ and another type of particles which does not contain Mn, (Figure 6). This result is consistent with that found by SEM technique and previous results reported by other workers $[12,13,17]$. Moreover, these authors added that the presence of particles, which contain $\mathrm{Mn}$ and Fe transition elements in addition to $\mathrm{Si}$, improves the mechanical properties of the material compared to the non containing Fe particles.

\section{Conclusion}

The thermal expansion coefficients changes versus temperature showed that the sheet which contains a relatively high level of Manganese expands less compared to the other sheet containing a high level of iron. A detailed analysis of the dilatometric curves suggests that the sheet 1 is more anisotropic than the other sheet. The latter material expands considerably along the perpendicular direction to the rolling plane ( $Z$ direction) compared to the former. The study of both materials by SEM and TEM techniques revealed the presence of thermally stable precipitates in sheet 1 . The presence of particles containing $\mathrm{Mn}$, in addition to $\mathrm{Fe}$ and $\mathrm{Si}$, justifies the good behavior of the corresponding material with temperature changes and also the improved mechanical properties of sheet 1 compared to that of sheet 2 . 
Citation: Saadallah S, Benaissa A, Boubertakh A, Hamamda S (2015) Dilatometric Study of Two based Aluminium Sheets. J Material Sci Eng 4: 150. doi:10.4172/2169-0022.1000150

Page 4 of 4

\section{References}

1. Cui J, Roven HJ (2010) Trans Nonferrous Met Soc China 20: 2057-2063.

2. Zhang XH, Su GC, Ju CW, Wang WC, Yan WL (2010) Effect of modification treatment on the microstructure and mechanical properties of $\mathrm{Al}-0.35 \% \mathrm{Mg}$ $7.0 \%$ Si cast alloy. Mater Design 31: 4408-4413.

3. Toda H, Nishimura T, Uesugi K, Suzuki Y, Kobayashi M (2010) Influence of high-temperature solution treatments on mechanical properties of an $\mathrm{Al}-\mathrm{Si}-\mathrm{Cu}$ aluminum alloy. Acta Mater 58: 2014-2025.

4. Vedani M, Angella G, Bassani P, Ripamonti D, Tuissi A (2007) DSC analysis of strengthening precipitates in ultrafine $\mathrm{Al}-\mathrm{Mg}-\mathrm{Si}$ alloys. J Therm Anal Calorim 87: 277-284.

5. Abid T, Boubertakh A, Hamamda S (2010) Effect of pre-aging and maturing on the precipitation hardening of an Al-Mg-Si alloy. J Alloys Comp 490: 166-169.

6. Guemini R, Boubertakh A, Lorimer GW (2009) Study of the recrystallization process of AIMgSi alloys containing transition elements. J Alloys Compd 486: 451-457.

7. Gong X, Li H, Kang SB, Cho JH, Li S (2010) Microstructure and Mechanical Properties of Twin-roll cast Mg-4.5Al-1.0Zn alloy sheets Processed by Differential Speed Rolling. Materials and Design 31: 1581-1587.

8. Gong X, Kang SB, Li S, Cho JH (2009) Enhanched Plasticity of Twin-roll cast ZK60 Magnesium alloy through Differential Speed Rolling. Materials and Design 30: 3345-3350.

9. Boulemzaoud K, Chahdane A, Saadallah S, Boubertakh A, Hamamda S (2011) $12^{\text {th }}$ International young Scientists Conference Optics and High Technology Material Science. Kyiv, Ukraine.

10. Boubertakh A, Benabdoun M, Hamamda S (2001) Etude dilatometrique de l'anisotropie d'une tole a base d'aluminium obtenue par solidification rapide. Ann Chim Sci Mat 26: 29-33.

11. Guemini R, Boubertakh A, Hamamda S (2001) Thermal expansion study of a "Direct Chill Casting" AIMgSi alloy. Eur Phys J AP 13: 167-170.

12. Cuniberti A, Tolley A, Castro Riglos MV, Giovachini R (2010) Influence of natural aging on the precipitation hardening of an AlMgSi alloy. Mater Sci Eng A. 527: $5307-5311$

13. Ke D, Hengcheng L, Qiumin J, Yun T(2010) Effect of hot extrusion on mechanical properties and microstructure of near eutectic $\mathrm{Al}-12.0 \% \mathrm{Si}-0.2 \% \mathrm{Mg}$ alloy. Mater Sci Eng A 527: 6887-6892.

14. Zhang XH, Su GC, Han YY, Ai XH, Yan WL (2010) A study on the composition optimization and mechanical properties of Al-Mg-Si cast alloys. Mater Sci Eng A 527: 3852-3856.

15. Aouabdia Y, Boubertakh A, Hamamda S (2010) Precipitation kinetics of the hardening phase in two 6061 aluminium alloys. Mater Lett 64: 353-356.

16. Panigrahi SK, Jayaganthan R, Pancholi V, Gupta M (2010) A DSC study on the precipitation kinetics of cryorolled Al 6063 alloy. Mater Chem Phys 122 188-193.

17. Quainoo GK, Yannacopoulos S (2007) Natural Aging Behaviour Of AA6111 Aluminium. Ghana J Sci 47: 91-100.

18. Birol Y (2006) J Therm Anal Calorim 83: 219-22. 